\title{
Un relato amnésico sobre la ciudad en Naciste pintada (1999) de Carmen Berenguer*
}

\author{
Angélica Franken** \\ Universidad de Chile \\ angiefranken@gmail.com
}

El presente análisis se centra en el poemario del año 1999 de la escritora chilena Carmen Berenguer (1946) titulado Naciste pintada. Específicamente, en la prosa poética contenida en la primera de las tres casas/imaginarios que da cuenta la autora llamada "Casa cotidiana", la que se encuentra territorializada en Plaza Italia y corresponde al lugar desde donde habla la voz poética femenina. Desde allí, esta lee la arquitectura de la ciudad (edificios, monumentos y plazas) como representación de un conflicto personal y colectivo entre lo viejo/histórico y lo nuevo que se afirma en la presencia de un relato amnésico sobre la ciudad que justifica la entrada de nuevos actores sociales - la figura del loco/a- al mapa urbano construido, quienes a su vez reescriben uno de carácter testimonial. testimonio.

Palabras clave: Mapa urbano, relato amnésico, actores sociales, casa,

The present analysis focuses on Carmen Berenguer's work of the year 1999, NacistePintada. The first one of the three houses/imaginaries that the author develops in her poetic prose is "Casa cotidiana". Situated on PlazaItalia, this house is the place where the feminine poetic voice is situated. The voice of the poem reads the architecture of the city (buildings, monuments, parks) as the representation of a personal and collective conflict between what it considers old/historic and new. The conflict arises from the presence of an amnesic account of the city which, at the same time, justifies the entrance of new social characters -such as the fool- to this urban map. Finally, these characters rewrite the story giving it a testimonial approach.

Keywords: Urban Map, Amnesic Image, Social Actors, House, Testimony.

Recibido: 27 de marzo de 2011

Aceptado: 10 de agosto de 2011

\footnotetext{
* El primer borrador de este texto fue escrito en el marco del seminario Poesía y Ciudad dictado por la profesora Magda Sepúlveda en el Programa de Magíster en Literatura de la Pontificia Universidad Católica de Chile a fines del 2008. Luego, fue presentado en el Congreso Internacional de Poesía Chile mira a sus poetas que se realizó en el mes de septiembre del 2009 en la misma casa de estudios.

** Estudiante del Doctorado en Literatura, mención Literatura chilena e hispanoamericana de la Universidad de Chile. Becaria CONICYT.
} 


\section{Introducción}

La cronista y poeta chilena Carmen Berenguer (1946) publica en 1999, en Cuarto Propio, el poemario titulado Naciste pintada que se articula en torno a tres casas y/o imaginarios: primero, "Casa cotidiana", que muestra Santiago y su centro urbano en movimiento y conflicto; luego, "Casa de la poesía", que tiene como escenario principal el prostíbulo porteño y santiaguino, y la historia de sus mujeres; y por último, "Casa inmóvil", que recoge el testimonio de varias mujeres en torno a su experiencia en la cárcel en tiempos de la dictadura militar en Chile.

Este análisis transita por "Casa cotidiana"; casa e imaginario del presente de la voz poética que se fija en Plaza Italia (cf. Berenguer 10). Desde allí, esta recorre y observa la arquitectura de la ciudad en los años 90 desde su quiebre personal, y luego colectivo, entre lo viejo/histórico y lo nuevo. Con base en este conflicto y en ese lugar de enunciación, construye poéticamente la denuncia de un relato amnésico de la historia de la ciudad; relato en el que reaparecen ciertos actores sociales olvidados o marginados, en este caso, los mapuches y sobre todo la figura del loco y la loca que desequilibra y resignifica precisamente este mismo discurso amnésico a la vez que configura, junto con y quizás gracias a la hablante lírica, un nuevo centro estratégico dentro de la ciudad, la casa.

Antes de comenzar con la imagen que la voz poética compone de la ciudad de Santiago, es necesario mencionar la dificultad en un nivel formal de situar dentro de un género definido este trabajo de Carmen Berenguer ${ }^{1}$. Como se menciona en la portada del libro, este texto transita entre la poesía y el recado, pero también dentro de la crónica, entendida esta como prosa poética, y como una escritura con alta referencialidad y actualidad, en la que la vida y su cotidianeidad se vuelven el centro (cf. Rotker 112). Todas características presentes en sus versos y que están en concordancia con el elemento histórico reflexivo que se encuentra latente en el poemario y que quiere rescatar particularmente este análisis. La presencia de los géneros referenciales de la crónica urbana y roja, y la carta, se une también a la narración testimonial que subyace a los tres imaginarios y/o casas conformados por Berenguer; vínculo con el testimonio que es profundizado en función de la voz enunciante que se asume femenina ${ }^{2}$ y de su lugar de habla.

\footnotetext{
1 Lorena Garrido, en su artículo "Naciste pintada de Carmen Berenguer o el desplazamiento de los géneros literarios/ sexuales", establece más profundamente las complejidades de situar este texto en un género particular, e, incluso, apela a que Berenguer realiza una ruptura con los géneros literarios; ruptura que le serviría también para realizar un desplazamiento del género sexual en su poemario (cf. 74).

2 En diferentes versos del poemario, la voz poética se enuncia como un yo femenino; enunciación de un yo que confirma un aspecto central de la crónica y de su presencia en este poemario: la igualdad entre el autor y el narrador, en este caso, voz poética. Sin embargo, este análisis se centrará en la configuración de la voz poética más allá de su cercanía al yo biográfico de Berenguer.
} 


\section{Las ruinas: lo nuevo en la ciudad}

En la primera parte del poemario titulada "Casa cotidiana", la hablante se adentra en la descripción de una serie de sitios, monumentos y edificios que componen la imagen visual y pública de un actual centro urbano de Santiago, Plaza Italia y sus alrededores. El sitio desde donde se observa el núcleo citadino se encuentra ahí mismo. Ella sitúa claramente su posición: "A mi derecha está el Parque Bustamante" (Berenguer 21). Desde esa ubicación estratégica, la primera impresión que se entrega de la ciudad es de una marcada por la presencia de nuevos edificios y productos de consumo. Es decir, la imagen de Santiago como ciudad moderna, en la medida que esta se articula como un centro de capital económico y de la experiencia de consumo (cf. Frisby 16).

[...] tiene paredes, tiene paredes blancas, tiene rejas, tiene perros rabiosos tras las rejas, tiene mercados, tiene malls, tiene edificios de vidrio, tiene edificios nuevos con más vidrios donde se reflejan nubes grises, tiene todo nuevo, tiene comunicaciones, tiene celulares, tiene policía, tiene policía nueva, tiene autos nuevos, tiene camas nuevas, tiene puertas nuevas, tiene ventanas nuevas, tiene metro nuevo, tiene bancos nuevos [...] (Berenguer 19)

De estos versos se extrae un campo semántico que relaciona la ciudad moderna a aquella con fuerte presencia de objetos de consumo -celulares, autos-, nuevas organizaciones para la obtención de estos -bancos, mercados, malls- y nuevos medios de seguridad y transporte de los mismos -rejas, policía y metro. Objetos, organizaciones y medios caracterizados por el adjetivo de nuevo.

Ahora bien, esta mercancía presente está asociada aquí, sobre todo, a lo extranjero, adquiriendo para la hablante estos productos con adjetivo ajeno no un valor novedoso, sino añejo y podrido.
[...] olor a fantasía añeja
olor a nafta
olor a pilchas europeas
olor a fajas gringas
olor a solapas gringas
olor a enaguas gringas [...] (Berenguer 19).

Estos versos refieren a cómo ahora en la ciudad circulan productos foráneos, bienes materiales como vestuario, pero también en otros poemas posteriores de "Casa cotidiana", alimentos de consumo masivo como el kétchup y las papas fritas que dan una nueva fisonomía y atmósfera -por segundos, nauseabunda- a los actos en la ciudad, a la vez que al sujeto urbano santiaguino que la transita velozmente. A su vez, este fragmento plasma a nivel de forma, en un verso breve y rápido, el mecanismo de obtención de productos acelerado y excesivo que caracteriza a una ciudad marcada por los bienes de consumo. 
Dentro de esta introductoria imagen general de la ciudad que recorre todo el poemario, se inserta la primera construcción que enuncia la voz femenina y que se contrapone posteriormente con aquella arquitectura relacionada con la historia de Chile. Este edificio corresponde al de la CTC (Telefónica Chile) que fue construido a mediados de la década del 90 frente al Parque Bustamante. Es presentado de la siguiente forma:

Al otro lado del Parque Bustamante se está construyendo el edificio más alto de Chile, es de la CTC. Se parece a los picos gemelos de Nueva York. Se parece a los picos gemelos de Chicago, se parece a la serie de T.V. de Lynch.

Es un celular gigante que recorta nuestra cordillera de Los Andes. Este es el panóptico de la ciudad de Santiago de Chile (Berenguer 28).

Es central la alusión a la imitación santiaguina de modelos/arquitecturas extranjeras, sobre todo estadounidenses, y a la forma de este edificio que es la de un celular -que tiene vidrios nuevos (cf.19)-, nuevo producto de consumo durante los años 90. La apreciación negativa de la hablante se percibe, ante todo, cuando señala que su arquitectura recorta nuestra visión de la cordillera -nuestra muralla natural-, ya que de esta manera establece una contraposición entre arquitectura/naturaleza; confrontación inarmónica que no se debe leer como una opción por el campo por sobre la ciudad en este poemario, sino como una distancia crítica ${ }^{3}$ a esa construcción en particular y su actual presencia omnipotente en la urbe. Se convierte en el nuevo ojo vigilante, en el nuevo panóptico de la ciudad. Entonces, el reciente poder se hace presente en la arquitectura, y su modo de ejercerlo sobre los sujetos es en forma de celular, es decir, de consumo.

Esta visualización de la ciudad bajo el sello eterno de lo nuevo y del consumo se conecta con la noción que se tiene sobre la ciudad moderna, como una que está en permanente cambio, y que construye lo nuevo sobre la ruina de lo pasado en su afán modernizador (cf. Berman 310). He aquí, pareciera, la gran tragedia de la modernidad, tener que destruir y construir permanentemente sobre lo que ella misma ha producido (cf. 310). Esta paradoja es presentada por la voz poética en este afán y renacimiento de lo nuevo como en sus propias afirmaciones de la ciudad de Santiago como ruina ${ }^{4}$, sobre todo, en los versos que dan inicio al poemario, titulado asimismo "Ruinas", donde revisita a Vicente Huidobro: "El poeta inglés pudo decir: 'Algo huele a podrido en Dinamarca', pero nosotros, más desgraciados

\footnotetext{
3 Para mayor profundización de este aspecto, Tatiana Calderón trabaja en su ensayo "Cartografía de la ciudad: la casa subversiva en Naciste pintada (1999) de Carmen Berenguer" las imágenes configuradas de la ciudad como también la crítica que se esconde en el poemario sobre el sujeto chileno.

4 La poeta chilena Marina Arrate identifica en su poemario Uranio del año 1999 también una voz poética femenina/masculina que hace un recorrido por la ciudad devastada por la guerra. Ruinas de esta ciudad moderna vinculada directamente con la mercancía al igual que en el poemario de Berenguer, lo que permitiría en un futuro estudio indagar en esta particular construcción e imagen de ciudad y la relación que ambas establecen con un pasado dictatorial.
} 
que él, nos veremos obligados a decir: Todo huele a podrido en Chile" (Berenguer 16). El motivo de destrucción y descomposición materializa la imagen poética de fondo del tiempo chileno que Berenguer espacializa, para este análisis, en el centro urbano de Santiago. La ruina estaría asociada a los restos de un pasado ahora quebrantado y fragmentado, que es suplantado por una nueva imagen. Lo nuevo es la ruina, lo nuevo es lo podrido, ya que "creo que tiene que ver con el olvido, /creo que tiene que ver con una madre muerta" (Berenguer 18).

Esta proyección poética de Berenguer pareciera tener eco en el acercamiento de Carlos Franz en su libro La muralla enterrada (2001) a la narrativa chilena sobre Santiago y los imaginarios urbanos ${ }^{5}$ que esta ha diseñado. En ese texto, el escritor chileno ilumina textos fundacionales y clásicos de la literatura nacional al tiempo que construye un mapa que busca explicar nuestra identidad: "[...] leer a Chile. Leerlo desde su capital y su imaginación" (16). Se vincula con "Casa cotidiana" de Naciste pintada en que también dibuja la sombra de la muerte sobre la ciudad, un Santiago mortal en cuyo centro amurallado "yace una tumba [...] símbolo de lo inmutable, de lo terminado" (59). Argumenta la resistencia chilena a los cambios, pero a la vez una insatisfacción latente y una escasez de pasiones heroicas que se sacian con deseos materiales en abundancia (cf. 59). Pareciera que la presencia perturbadora del negocio asociada a la ruina y al olvido -nuestro "peso de la noche" (cf. 59)- sacia nuestras frustraciones y olvidos.

\section{Mapas urbanos de un relato amnésico}

El quiebre visual que dibuja "Casa cotidiana" se justifica y ancla en la presencia de un relato amnésico de la historia; relato que reordena y reconfigura la relación de la voz poética femenina como la de otros sujetos urbanos con la misma ciudad (cf. Reguillo 166). Este se conecta directamente, en un contexto histórico y cultural, con el proceso de transición democrática chileno que se instauró sobre la base gubernamental de un afán político conciliador que necesitaba olvidar un pasado dictatorial y construirse sobre el acto simbólico del consenso (cf. Moulián 43) para crear un nuevo Chile democrático y globalizado, marcado por las improntas y estrategias de una economía y política neoliberal de apertura a los mercados e influencias extranjeras. En "un sistema de trueques: la estabilidad, se dijo, tiene que ser comprada con el silencio" (32).

Con el fin, aparentemente, de deslegitimizar este discurso y mostrar lo que fue ocultado y blanqueado, la voz poética describe y conforma un imaginario urbano paralelo, un relato de la ciudad propio (cf. Canclini 93), trazado a nivel espacial, entre muchos otros, por la diagonal Plaza Italia-cerro Huelén y Estación Mapocho, y poblado por ciertos actores sociales que tienden a desequilibrar este discurso amnésico y a levantar la voz como anunciadores

\footnotetext{
5 Para una futura investigación, resultaría interesante hacer una comparación entre los mapeos urbanos que construye Franz en relación con los de Berenguer, siendo el texto de ella anterior y más cercano al formato testimonial.
} 
del desagravio y el mal. Específicamente, estos personajes son la comunidad mapuche, el loco del monumento a Baquedano y la loca obrera travestí.

Estos sujetos se apropian de ciertos espacios particulares de la ciudad para, desde allí, vitorear su discurso que dialoga con una historia pasada, resignificándola. Un primer espacio reformulado que introduce la voz poética de "Casa cotidiana" es el cerro Huelén y la comunidad mapuche:

Entremedio de todo, hoy 12 de octubre es el día de la raza. 300 mapuches subieron al cerro Huelén.

Denunciaron la explotación que realizan los empresarios nacionales en sus territorios originarios.

"Solicitamos", dijeron: "que se respete la existencia pacífica de los cuatro colores humanos" (Berenguer 20)

La comunidad sube al cerro Huelén, nombre en mapundungun del cerro Santa Lucía; lugar histórico clave en la fundación hispánica de la ciudad de Santiago en el año 1541; terreno emblemático de la historia de Chile que ha sufrido varias transformaciones a lo largo de los siglos y que, en la actualidad, debido a los aportes de Benjamín Vicuña Mackenna y sus viajes por Europa, presenta desde principios del siglo XX una arquitectura francesa y se proyecta como un lugar de paseo y recreo similar a los conocidos en el Viejo Continente. Lo que resulta emblemático es que la comunidad mapuche escoja un lugar relacionado con la dominación hispánica, como una fecha también emblemática para el conquistador, para pronunciar un discurso de apertura racial y respeto a su etnia. En el lugar simbólico de la conquista, el pueblo mapuche pide a los chilenos, en el lenguaje oficial -el español-que tampoco le pertenece, que se respeten sus derechos. El lugar, la fecha, el lenguaje y el discurso dan cuenta de su condición de pueblos subyugados y de portadores de una cultura ajena. Desde esa perspectiva, se puede interpretar este acto en el cerro Huelén como la confirmación de una historia de dominación y resentimiento, o como el intento de producir en un espacio simbólico de la influencia extranjera en Chile un discurso que entra en crisis con la realidad chilena en la medida que recuerda un origen étnico despreciado y olvidado, y lo hace con los códigos del dominador, acortando, o quizás anulando, de este modo las distancias sociales. Por esto mismo, la inserción que hace la voz poética femenina de este grupo en la ciudad, respalda una mirada particular sobre esta misma, que defiende la presencia de varios relatos contradictorios, pero ante todo discursos que interrumpen el estado amnésico que había dejado la Conquista del conflicto mapuche en la historia del pueblo chileno.

El segundo espacio fundamental del imaginario urbano construido por la hablante es la Estación Mapocho. En una primera instancia, destaca el tono crítico y nostálgico de la voz poética que se sitúa personalmente en relación con ese lugar.

6 Berenguer altera con fines, seguramente, poéticos sonoros la acentuación correcta del término. 
He reconstruido mi viaje entre la ciudad donde fui concebida, Valparaíso y mi ciudad de Santiago. Entre ellas recorrí mi infancia, en torno a sus plazas, mi viaje literario tiene un especial callejeo primario en el cité frente a la plaza Artesanos, construcción imitativa francesa, cerca de la Estación Mapocho donde se estrechaba el camino con Valparaíso, hoy convertido en el mercado de la literatura (Berenguer 26)

Ella establece un quiebre entre lo que la Estación Mapocho representaba en el pasado -un lugar de llegada y partida entre las dos ciudades de su infancia- con el rol que cumple en la actualidad el edificio donde se celebra la mayor feria del libro del país. El tono crítico de la voz femenina frente al último aspecto es claro y se evidencia que la función que ha adquirido este en los últimos años es radicalmente opuesta a la del pasado, relativa a un contexto de encuentro y viaje: el tren. Lo relevante de estos versos no es tan solo la constatación de una mirada conflictiva de la hablante entre un pasado, al parecer, mejor y un presente ajeno, sino precisamente su aparente intención de romper con el relato amnésico de la ciudad al recordar que en las inmediaciones del barrio Mapocho se encuentra un edificio clave de nuestra historia política reciente: "Allí está situada la casa de la tortura chilena, ¿recuerdan? En Borgoño 1470" (26). La inserción consciente de esta construcción confirma su presencia en este imaginario urbano propio y, por ende, en la interacción de la voz poética con la ciudad como, a su vez, también en la finalidad de que su implicancia social reaparezca en el mapa urbano macro de Santiago. Esta última intención se visualiza en la imagen fotográfica de esta casa que recorre los tres imaginarios conformados por Berenguer en Naciste pintada; imagen que en "Casa cotidiana", armada en el presente de la ciudad, se caracteriza por estar borrosa, es decir, simbólicamente, en proceso de olvido; proceso que justamente quiere interrumpir la voz poética al hacer su presencia patente en el recorrido personal por la ciudad como al situar esta casa -mediante la fotografía- como el eje/espacio histórico central y unificador de todo su poemario; conexión explícita con un pasado histórico, el régimen militar en $\mathrm{Chile}^{7}$, que el relato amnésico y neoliberal reciente ha suplantado.

Finalmente, el tercer espacio en el imaginario urbano construido por la voz poética es el de Plaza Italia. En el inicio de este análisis se menciona que allí es desde donde habla la voz poética femenina. Ahora, la caracterización que hace esta de ese lugar es de un centro neurálgico, de movimiento y división.

La Plaza Italia símbolo mítico de las últimas manifestaciones públicas, señalaría el límite de nuestras fijaciones.en la distancia, entre los de arriba, y los de abajo. Fijaron la diferencia en nuestras heridas.

\footnotetext{
7 En los otros imaginarios, "Casa de la poesía" y "Casa inmóvil", la conexión con el tiempo de dictadura es más directa, ya que están construidos con testimonios, cartas y crónica roja de esos tiempos; relación que en "Casa cotidiana" se vislumbra mediante la crítica detrás de un sistema neoliberal y en la configuración del imaginario urbano de la voz poética.
} 
Fijaron la diferencia entre lo liviano y lo pesado.

Fijaron la diferencia entre los hijos de nadie y los hijos de alguien. Fijaron la frontera entre ellos y nosotros.

(Berenguer 24)

La Plaza Italia y, en ella el monumento a Manuel Baquedano, ocupa dentro de la ciudad un espacio de varias significaciones. Esto en la medida que se configura como centro de una división socioeconómica e, incluso, de una política e histórica. Jorge Lizama en su estudio de la capital chilena reafirma que la Plaza Italia se yergue efectivamente como una frontera entre el Chile de abajo y el Chile de arriba (cf. 59). La marca textual en el poema de esta división política e histórica es la palabra "heridas" que alude a una confrontación existente en el pasado y que ha dejado sus huellas en los sujetos y su marca espacial en esa Plaza; lugar desde y donde los sujetos urbanos ahora se expresan. Efectivamente, desde el triunfo del No y la transición democrática en adelante todas las manifestaciones políticas, deportivas, de género, entre otras, se han celebrado allí, instaurándose la Plaza y su monumento como el espacio preciso para escuchar y desde donde hablar al país, como el sitio por excelencia para mirar Chile.

Sin embargo, es necesario destacar que este lugar se ha llenado de significado para la voz poética como frontera, como división; división instaurada por una tercera persona y/o acontecimiento que en los versos es omitido: ¿quién fijó las distancias entre las heridas, entre ellos y nosotros? Tras lo mencionado y el nuevo rol que adquiere este espacio para cierto grupo sociopolítico a contar de los procesos de la democracia en Chile, es posible que esta fractura espacializada en Plaza Italia tenga su conexión directa, para la hablante lírica, con los tiempos del régimen militar y las repercusiones sociales y morales de este en la sociedad chilena.

Esta separación sociocultural se expresa también a nivel arquitectónico en la misma Plaza Italia, en la elevación de la CTC a metros de ella; construcción que no solo perturba la vista sobre la cordillera de los Andes, sino ante todo resalta la contradicción de discursos que encarna su fisonomía respecto del monumento al general Baquedano. Siguiendo esta lectura, ahora la Plaza Italia es el mejor lugar para mirar Chile y el edificio CTC se convierte en el nuevo observatorio de la sociedad chilena. Quiebre visual e ideológico que permite la entrada de nuevos actores sociales al panorama urbano imaginado en "Casa cotidiana".

\section{La figura del loco/a y el testimonio}

La voz poética femenina de "Casa cotidiana" transita desde un "yo" a un "nosotros" para referirse a otros que como ella tienen su centro en la Plaza Italia, a los que introduce en esta nueva fisonomía citadina y en su relato amnésico: la figura del loco y la loca. Ellos estarían dentro del grupo "nosotros" iniciado por la hablante; no obstante, en una primera lectura, no queda tan claro si estos sujetos tienen una voz y un lugar propio dentro del núcleo urbano o si su presencia es la representación de la hablante femenina 
que habla por los otros desde su posición estratégica en el nuevo centro de Santiago: "Son las 7 de la tarde y aquí donde yo vivo de tiempo en tiempo nuevos locos se allegan a la Plaza Italia [...]" (Berenguer 40). La voz femenina observa/mira desde la ventana de su casa a la ciudad moderna en su calidad de vitrina (cf. Silva 124). Mira, pero no puede ser vista por estos otros -locos y locas- que transitan la ciudad. Es testigo ocular y auditiva de sus dichos, pero estos no se saben vistos ni oídos, ya que la voz poética habla y observa desde la casa y este estar fuera de la calle y dentro de la casa -este lugar protegido, que permite la evocación (cf. Bachelard 36), y que suele estar atribuido a la mujer- establece una distancia con estos sujetos que son dejados hablar.

Ahora bien, el loco y la loca como protagonistas locales aparentemente representados o, por el contrario, poseedores de una voz y verdad propia tienen un mensaje que desestabiliza el silencio u olvido -que se ha relacionado en este análisis con la política conciliatoria de la transición democrática- y sitúan a la Plaza Italia no solo como lugar de paso y de lo nuevo, sino una vez más como lugar espacial de enunciación y observación. Es ahora la figura de un loco que se sube al caballo de Manuel Baquedano a gritar a viva voz y los dichos de una voz femenina -"que con énfasis y energía, apenas se oía entre la multitud de personas" (Berenguer 29)- la que desde la Plaza Italia reverberaba:

[...] Para que esta ciudad se levante ha debido hacerlo sobre el lomo de la pobreza $[\ldots]$.

Para que esta ciudad se levante ha debido pisar, para que pretenda ser ciudad del mundo ha debido matar [...].

En esta ciudad ha surgido una nueva riqueza $[\ldots]$.

El simulacro de los posmodernos le ha servido a su nueva facha (Berenguer 29).

El cambio económico y social ha trazado una nueva fachada de la ciudad, y en relación con el análisis realizado en los apartados previos, la clave interpretativa del poemario es la crítica acérrima a la vida cotidiana, a la construcción de lo nuevo por sobre un pasado. En este caso, a la construcción de una riqueza sobre una pobreza aún existente. Por esto mismo, la nueva imagen de Santiago es un simulacro, finge tener lo que no tiene, hay una nueva riqueza, pero la loca excitada recordará que la pobreza aún existe también y que la nueva riqueza es nueva esclavitud (cf. 29). Que esta crítica a la vida cotidiana de este actor social sea efectivamente desde la Plaza Italia refuerza nuevamente el valor histórico de este lugar, como espacio para mirar Chile y sus nuevas estrategias al oriente y poniente.

Esta voz elocuente, lúcida y sin miedo -recordemos la figura del loco/a como una poseedora de la "verdad" (cf. Morales, 2008: 92)- da lugar a la performance de la obrera loca travestí que la voz poética enuncia y destaca entremedio de las masas que pasan por frente al caballo de Baquedano y frente a sus ojos (cf. Berenguer 40). Lo fundamental de su presencia es 
que ella se construye como una suerte de figura histórica; en ella corre el pasado y el presente.

Esta es una loca travestí fantasmal, que recuerda las uniones obreras de principios de siglo, y que perfectamente podría, sin proponérselo, convocar a los nuevos humillados de este final.

Nómade urbana, atraviesa sin miedo entre las gentes, perpetuando el sarcasmo y ruin fracaso y húmedo y siniestro espectro de ciudad nueva (40).

La obrera loca travestí pertenece a los vencidos, pero su cuerpo rememora un pasado olvidado en el simulacro urbano. Son sus aseveraciones, como en el caso de la comunidad mapuche o del loco que grita en Plaza Italia, los que dan cuenta una vez más de este conflicto entre pasado y presente latente en los versos. Y ahora también su corporalidad y sus actos sociales visibles se articulan como transgresores, ya que rompen con la práctica sexual que le ha asignado la norma a su cuerpo (cf. Butler 18). Esto último la vincula nuevamente con el imaginario de la locura, ya que la ruptura de ciertas prohibiciones morales y sexuales introducía inmediatamente al sujeto en ese universo (cf. Foucault 274). De ese modo, con sus dichos de "verdad" y su cuerpo, la loca travestí desequilibra el relato amnésico y simulacro de ciudad nueva que la voz poética denuncia.

Cabe preguntarse si la opción de Berenguer por este actor social confirma o deconstruye el mundo de la locura construida por la ciudad y sociedad chilena -recordemos que el manicomio y los muertos, los negados, estaban al otro lado del Mapocho, en el barrio de la Chimba- (cf. Franz 23). Lo que sí, es que los locos son los que se atreven a hablar o dicen lo que otros callan, y le otorgan nuevamente una función que se había perdido en el uso generalmente solo de tránsito, de paso, de las calles de Santiago desde los años 70 y 80 en adelante (cf. Lizama 60). En este sentido, Berenguer no "estetiza" la figura de loco $/ a^{8}$, sino que la "espacializa" en el imaginario de la ciudad. Sin embargo, qué sucede con la voz poética femenina que, por instantes, deja hablar libremente en sus versos a estos sujetos y en otros momentos reproduce sus discursos. Este permitir hablar a los otros, que están afuera y son vistos, se convertiría en la única forma que tiene de expresarse, en su urgencia de que se expresen por ella o, por el contrario, este dejar denunciar a los otros e introducir sus figuras en la fisonomía de la ciudad como elementos conflictivos, sería el modo de encontrar un discurso propio, ajeno a las

8 Una referencia clara de una relato testimonial donde también se trabaja con la locura son los textos de la escritora chilena Diamela Eltit, Padre mío (1989) y El infarto del alma (1994). Hay aspectos en común entre esta obra y la de Berenguer, no obstante, el trabajo de esta última está más centrado en situar a estos sujetos fuera de la norma precisamente porque son capaces de hablar lúcidamente y portan una "verdad" sobre la historia. En el caso de Eltit, los sujetos en la locura significan en sí mismo la ruina del sujeto, de la sintaxis, del discurso (cf. Morales, 2008:76). Por ello, estos, a mi juicio, poseen en menor medida el sitial de revelación y transformación que sí tienen los locos de Casa cotidiana, ya que estos gritan y producen cambios en la ciudad misma y en el relato que se ha imaginado de ella. 
nuevas regulaciones de poder que denuncia (cf. Certau L). A fin de cuentas, la pregunta es si para Berenguer el loco o la loca podrían o no hablar por sí mismo, y qué se esconde detrás de esta opción poética. Quizás solo el loco o la loca podrían transparentar los mecanismos expuestos.

Lorena Garrido, en su estudio sobre Naciste pintada, va a destacar el intento presente en el poemario de Berenguer de rescatar la voz de los oprimidos, entre ellos, particularmente, las mujeres y los locos (cf. 77). Propósito que se vincula de modo directo con el género testimonial ${ }^{9}$ entendido como un relato no ficcional donde la verdad es invocada para denunciar una situación de opresión o para corregir la historia oficial (cf. Yudice 44). En este sentido, es posible leer este poemario como el intento de rescatar poéticamente el discurso de los marginales, pero, más bien, el valor artístico se encuentra en situar en ellos una posible salida a este relato amnésico, que recorrige la historia oficial, si es que esta existe. En la carta ${ }^{10}$ introductoria al poemario Naciste pintada, la autora introduce lo siguiente: "En este tiempo posmoderno, donde no se puede hacer una teoría conceptual de la historia, lo único que vale es el testimonio, la voz de cada una como vivió esa historia que circuló por las calles, que fue 'oficial'"' (Berenguer 10). Afirmación que en el caso de "Casa cotidiana" no se plasma en testimonios y cartas directas de prostitutas y mujeres encarceladas de "Casa de la poesía" y "Casa inmóvil", sino en una voz poética anclada en la casa del presente que deja gritar, sin decir que lo hace, a los portadores de una historia y una imagen de la ciudad paralela a la oficial. Por ello, no solo en sus cuerpos cansados y travestidos y sus palabras vociferantes está el elemento subversivo, sino en lo que ellos llevan consigo: el recuerdo, la memoria.

Esto último se relaciona con el hecho de que la voz poética femenina habla desde un lugar protegido, su casa, espacio desde donde puede mirar privilegiadamente el espectro de la ciudad y sus movimientos. Teniendo en consideración que esta ha sido el lugar por excelencia asociado a la mujer y su rol social y la calle, y el espacio público, el del hombre, el sitio de enunciación de la voz poética es acorde al discurso hegemónico y no posee, aparentemente, ninguna ruptura con este en confrontación a la loca lúcida que gritaba al igual que el loco en medio de Plaza Italia y que sí establecía una estrategia, al salir de su doble marginalidad de mujer y loca, por medio de un discurso propio que además rearticula y se distancia de su habitual lugar en la sociedad (cf. Certau L).

Ahora bien, la casa adquiere en "Casa cotidiana" un nuevo significado que resemantiza completamente su valor asignado; sigue siendo el lugar de la mujer, pero es aquel donde esta rememora y apela al recuerdo

\footnotetext{
9 Para efectos de este análisis, se señalan algunos puntos teóricos claves del testimonio bajo el supuesto de que es un género no cerrado, sino abierto a permearse con otros formatos narrativos y, en este caso en particular, con la prosa poética de Berenguer que en el apartado Casa cotidiana sigue la forma lírica. Para este análisis es impensable el género puro en su formato canonizado por la Academia en la década del 80.

10 Esta carta -género referencial también- que actúa a modo de prólogo y guía de lectura del poemario vincula nuevamente estos versos con los textos testimoniales clásicos latinoamericanos, en los que el paratexto del prólogo suele justificar y orientar las lecturas.
} 
colectivo e histórico. Ya no es solo el lugar de protección y ensoñación (cf. Bachelard 36), sino que allí convergen y se reproducen diferentes identidades y discursos políticos (cf. Lewis 71). De esa manera, el lugar y la labor asignada a una voz femenina se transforma en un elemento que subvierte y en discurso propio, es decir, en una estrategia (cf. Certau L). A fin de cuentas, qué mejor modo de resignificar este rol que en el lugar que el mismo relato amnésico descrito le ha asignado en su programa de privatización del espacio público y de repliegue al privado. La voz poética utiliza las tretas del débil, conoce el imaginario asignado a su género, por ende, no sale de la casa, deja hablar a otros que hablan por ella, aparenta no saber sabiendo (cf. Ludmer 48).

\section{Últimas observaciones}

Finalmente, la mirada conflictiva entre lo viejo y lo nuevo que trasluce la voz poética a lo largo de "Casa cotidiana" encuentra su plasmación y su salida en una prosa poética y en unos actores sociales que trazan mapas urbanos alternativos, que apelan al recuerdo, que denuncian el simulacro y la ruina, y que articulan sus discursos cercanos al género del testimonio latinoamericano. Cabe señalar que Berenguer aborda más o menos directamente los rasgos principales del género del testimonio: la presencia de un testigo y de alguien que quiere escuchar, la urgencia de denunciar un hecho de opresión, la dificultad y/o cinismo de hablar por otros, la transparencia y el vínculo histórico temporal que exige el formato (cf. Yudice 44), y construye un texto literario permeable con protagonistas que precisamente podrían ser omitidos de atestiguar por su condición mental y por la posición que han ocupado en la sociedad contemporánea, y que en la literatura sí encuentran un espacio abierto y verosímil para hablar.

Por último, esta prosa poética vinculada a la narración testimonial permitiría resignificar el espacio doméstico, como a su vez sería esta una estrategia propia de las mujeres para salir simbólicamente del espacio privado al público (cf. Calderón 74). Lo anterior gracias al carácter testimonial que subyace al género referencial ${ }^{11}$ (cf. Morales, 2001: 25) de la crónica urbana que utiliza la voz poética y que defiende la cercanía de esta con el yo biográfico de la escritora chilena. Por ello, un tipo de relato que expresa líricamente un yo y nosotros incluyente que, por momentos, parece ser Berenguer; por otros, la loca; y que en los distintos imaginarios que pueblan todo el poemario de Naciste pintada, ocupa el lugar de las prostitutas, lesbianas, travestís, madres, viudas, presas políticas y muchas otras mujeres que desde sus diferentes casas rememoran ${ }^{12}$ una historia y, sobre todo, una herida social y política que, para Berenguer, todavía está latente en la fisonomía de la ciudad.

\footnotetext{
11 Leonidas Morales (2001) establece las distinciones entre género referencial y discurso testimonial, otorgándole a este último un valor transhistórico y transgenérico supeditado bajo la forma de los géneros referenciales de la crónica, carta, autobiografía y diario íntimo. 12 Pienso en otras casas del recuerdo femenino: Mapocho (2002) de Nona Fernández, La sagrada memoria: reminiscencias de una niña judía en Chile (1994) de Marjorie Agosín, Tiempo que ladra (1991) de Ana María del Río, La casa de los espíritus (1986) de Isabel Allende, entre otras.
} 


\section{Obras citadas}

Arrate, Marina. Uranio. Santiago de Chile: LOM, 1999.

Bachelard, Gastón. La poética del espacio. México DF: Fondo de Cultura Económica, 1993.

Berenguer, Carmen. Naciste pintada. Santiago de Chile: Editorial Cuarto Propio, 1999.

Berman, Marshall. Todo lo sólido se desvanece en el aire. Decimosexta edición. México DF: Siglo XXI Editores, 2006.

Butler, Judith. Cuerpos que importan. Sobre los límites materiales y discursivos del "sexo". Trad. Alcira Bixio. Buenos Aires: Paidós, 2002.

Calderón, Tatiana. "Cartografía de la ciudad: la casa subversiva en Naciste pintada (1999), de Carmen Berenguer", en Bifurcaciones $N^{\circ} 4$ (2005) [www.bifurcaciones.cl].

Certau, Michel de. La invención de lo cotidiano. I Artes de Hacer. Trad. Alejandro Pescador. México DF: Universidad Iberoamericana, 2000.

Eltit, Diamela. 1989. El Padre mío. Santiago: Francisco Zegers Editor, 1989.

Eltit, Diamela y Paz Errázuriz. El infarto del alma. Santiago: Francisco Zegers Editor, 1994.

Franz, Carlos. La muralla enterrada. Santiago de Chile: Planeta, 2011.

Frisby, David. Paisajes urbanos de la modernidad. Buenos Aires: Universidad Nacional de Quilmes, 2007.

Foucault, Michel. Entre Filosofía y Literatura. Obras esenciales. Trad. Miguel Morey. Barcelona: Paidós, 1999.

García Canclini, Néstor. Imaginarios urbanos. Buenos Aires: Eudeba, 1999.

Garrido, Lorena. "Naciste pintada de Carmen Berenguer o el desplazamiento de los géneros literarios/sexuales", en Acta Literaria N 36, 2008.

Lewis, Tyson y Daniel Cho. "Home is where the neurosis is. A Topography of the spatial unconscious", en Cultural Critique 64, 2006.

Lizama, Jaime. La ciudad fragmentada. Espacio público, errancia y vida cotidiana. Santiago de Chile: Ediciones Universidad Diego Portales, 2007.

Ludmer, Josefina. "Las tretas del débil", en El sartén por el mango. Ed. Patricia Elena González. Río Piedras: Editorial Huracán, 1985.

Morales, Leonidas. La escritura de al lado. Géneros referenciales. Santiago de Chile: Cuarto Propio, 2001.

De muertos y sobrevivientes. Narraciones chilenas modernas. "La verdad del testimonio y la verdad del loco". Santiago de Chile: Cuarto Propio, 2008.

Moulián, Tomás. Chile actual: anatomía de un mito. Santiago de Chile: LOM, 2002.

Reguillo, Rossana. Más allá de la ciudad letrada. Comp. Boris Muñoz y Silvia Spitta. Pittsburgh: U. de Pittsburg, 2003.

Rotker, Susana. La invención de la crónica. Argentina: Ediciones Letras Buenas, 1992.

Silva, Armando. Imaginarios urbanos: Bogotá y São Paulo. Bogotá: Tercer Mundo Editores, 2000.

Yudice, Georg. "Testimonio and posmodernism", en The real thing. Ed. Georg Guggelberger. Durham and London: Duke University Press, 1996. 